Dismantling the Medieval studies the paradoxical relationship of the early modern canonesses of Bouxières abbey with the medieval past of their institution. While various documentary, material, spatial, and immaterial legacies of that past remained a crucial presence in the convent's narrative of self, the canonesses also used and manipulated them to pursue and justify drastic changes in their organization and lifestyle. Thanks to an unusually rich and varied body of evidence, we are able to reconstruct in unprecedented detail this elite convent's memory culture over a period of more than two centuries. We see how it was expressed and how it evolved, and what were the factors that drove forward its development. The resulting image of a highly flexible memorial culture helps us to explain how and why it lived on throughout many crises and transformations, including even the abbey's dissolution in I79I.

STEVEN VANDERPUTTEN is a full professor in the history of the early and high Middle Ages at Ghent University. He specializes in the study of the culture and societal embedding of religious communities, with a particular focus on memory culture, leadership, and reform. His monographs include Monastic Reform as Process (2013) and Dark Age Nunneries (2018). Recently he has extended his research into the early modern period, looking at long-term trends in the perception of the medieval past.

\section{Dismantling the Medieval}

\author{
Early Modern Perceptions of \\ a Female Convent's Past
}

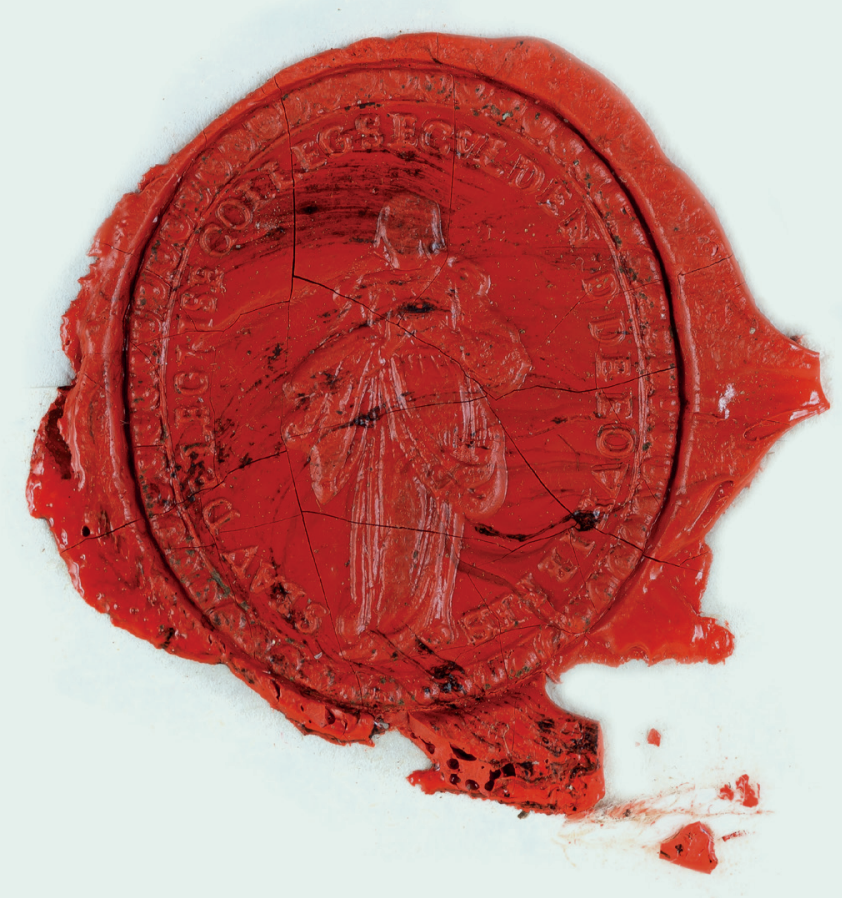

STEVEN VANDERPUTTEN 